\title{
O uso do pavimento para geração de energia e desenvolvimento sustentável de cidades inteligentes
}

\section{The use of pavement for energy generation and sustainable development of smart cities}

\author{
Bruno Cavalcante Mota ${ }^{1}$, Suelly Helena de Araújo Barroso ${ }^{2}$ \\ 1Universidade Federal do Ceará, Ceará - Brasil, brunomota@det.ufc.br \\ ${ }^{2}$ Universidade Federal do Ceará, Ceará - Brasil, suelly@det.ufc.br
}

\section{Recebido:}

19 de maio de 2020

Aceito para publicação:

8 de janeiro de 2021

Publicado:

16 de agosto de 2021

Editor de área:

Francisco Thiago Sacramento

Aragão

\section{Palavras-chave:}

Piezoeletricidade.

PZT.

Simulações.

Energia mecânica.

\section{Keywords:}

Piezoelectricity.

PZT.

Simulations.

Mechanical energy.

DOI:10.14295/transportes.v29i2.2380

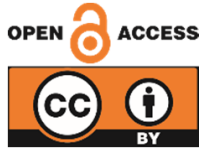

\begin{abstract}
RESUMO
O pavimento rodoviário possibilita a obtenção de energia elétrica por meio da transformação da energia mecânica transmitida pelos veículos à sua estrutura. Nesse contexto, este artigo foi desenvolvido com o objetivo de investigar o pavimento como mecanismo de geração de energia, por meio da piezoeletricidade, para contribuir na redução do impacto ambiental relativo às energias. Foram realizadas simulações multifísicas em sete geometrias de células piezoelétricas, em caráter estacionário, e em um protótipo com arranjo de quatro células da que apresentou melhores resultados na etapa anterior, em caráter dinâmico. Dessa forma, verificou-se que a espessura da célula é a propriedade geométrica que mais influencia no potencial elétrico gerado. A partir do protótipo proposto seria capaz de serem gerados $306,37 \mathrm{MW}$ de potência elétrica por ano. Além disso, sugere-se que trechos de rodovias interestaduais, com alta velocidade e volume de tráfego, e vias expressas seriam bons candidatos para aplicação do sistema piezoelétrico.
\end{abstract}

\section{ABSTRACT}

The road pavement makes it possible to obtain electrical energy by transforming the mechanical energy transmitted by the vehicles to his structure. In this context, this article was developed with the objective of investigating the road surface as a mechanism of energy generation, by using piezoelectricity, to contribute to the reduction of the environmental impact relative to energy. Multiphysical simulations were performed in seven geometries of piezoelectric cells, in a stationary character, and in a prototype with an arrangement of four cells of the one that presented the best results in the previous stage, in a dynamic character. Thus, it was verified that the cell thickness is the geometric property that most influences the electric potential generated. From the proposed prototype it would be possible to generate $306,37 \mathrm{MW}$ of electric output per year. In addition, it's suggested that sections of interstate highways, with high speed and traffic volume, and expressways would be good candidates for application of the piezoelectric system.

\section{CONSIDERAÇÕES INICIAIS}

A sustentabilidade, conforme Elkington (1999), só é possível com a consideração conjunta das esferas social, econômica e ambiental. Ela é comumente atrelada ao desenvolvimento sustentável, no qual se destaca o tema de energias e o desperdício de recursos naturais. A dependência de energia da sociedade atual torna essa temática estratégica para qualquer país. 
Além disso, a transversalidade do tema de energia faz com que esse apresente uma relação com setores econômicos e sociais (CEARÁ, 2018a).

O Estado do Ceará vive um processo de fortalecimento e diversificação de sua matriz energética com a inclusão de outras fontes renováveis (solar, eólica, proveniente de hidrelétricas, etc) que não podem ser consideradas de forma fragmentada e com visão estritamente econômica. Essa consideração corre risco de promover impactos ao sistema natural, incluindo a perda de recurso, principalmente nas atuais condições de constantes mudanças climáticas (CEARÁ, 2010 e $2018 b$ ).

Existe uma demanda internacional com relação à geração de energia e ao uso de tecnologias mais limpas para sua produção. Há preocupação com a utilização de fontes não-renováveis e a possível escassez de recursos hídricos para o caso das hidrelétricas. Em contrapartida, nas cidades os veículos deslocam-se sobre pavimentos, liberando energia mecânica para os mesmos. Essa energia, normalmente, não é captada e nem utilizada, contudo, pode ser convertida em energia elétrica (Duarte e Ferreira, 2016).

Quando se buscam alternativas sustentáveis de geração de energia, que não dependam do sistema natural, o pavimento pode passar a ser considerado. Ele é visto como o ponto de encontro de pessoas e veículos, um local ideal para a geração de energia renovável. As variáveis dependentes seriam apenas o movimento habitual sobre sua estrutura, permitindo a conversão da energia mecânica dissipada em energia elétrica.

Santos (2014) ressalta que o pavimento deixa de ser apenas funcional e estrutural, passando a contribuir diretamente com o desenvolvimento sustentável, produzindo e armazenando energia elétrica. Essa energia pode ser utilizada na própria infraestrutura rodoviária, alimentando sistemas de iluminação, semáforos e, ainda, no abastecimento de redes elétricas de edifícios residenciais, comerciais e industriais que se localizem próximo à via. Contudo, Roshani et al. (2018) evidenciam que o sistema de captação de energia não deve gerar impactos na integridade estrutural do pavimento e nem interromper o fluxo de veículos.

Dada à inovação do assunto, acredita-se que o tema energia versus pavimentação deverá ser foco de pesquisas brasileiras nos próximos anos para incentivar o desenvolvimento de cidades inteligentes. Sendo assim, o estudo aqui apresentado tem o objetivo geral de investigar o pavimento como instrumento de geração de energia piezoelétrica, abordando como esse pode ser útil na geração de energias limpas. Para tanto, também foram estabelecidos objetivos específicos, tais como: (i) realizar uma revisão bibliográfica acerca da piezoeletricidade, tendo em vista que o assunto é relativamente novo na área de pavimentação; (ii) simular os modos estáticos e dinâmicos de diferentes células piezoelétricas para analisar potencial e estresse máximos e (iii) propor um protótipo de geração de energia piezoelétrica aplicado a um trecho rodoviário.

\section{REVISÃO BIBLIOGRÁFICA}

Energy Harvesting (Captação de Energia) é um tema da engenharia que aborda a captação, a conversão e o armazenamento de energias renováveis. Além das fontes de energia já conhecidas como a hídrica, eólica, solar, térmica e energia dos oceanos, recentemente, algumas pesquisas vêm utilizando o pavimento rodoviário como uma fonte geradora de energia. Uma das principais formas de energia renovável obtidas através dos pavimentos é a energia mecânica, liberada pelo tráfego de veículos. Essa energia, se captada, pode ser convertida em energia elétrica (Andriopoulou, 2012). 
De acordo com EPE (2019), a maior fatia da matriz energética do Brasil atualmente está com o petróleo e derivados, representando 34,50 \% da produção interna total de energia. Contudo, no que se refere à matriz elétrica, o Brasil possui $66,60 \%$ de sua energia elétrica proveniente de usinas hidrelétricas que, a depender do clima, podem entrar em escassez e culminarem no acionamento das termoelétricas, por exemplo, que causam impactos ao meio ambiente e à população.

A piezoeletricidade funciona por meio de sensores piezoelétricos que, ao sofrerem alterações dimensionais, devido às tensões mecânicas aplicadas, geram energia. Isso acontece porque os cristais piezoelétricos são compostos de átomos eletricamente neutros em seu interior, sem arranjo simétrico e com cargas elétricas perfeitamente balanceadas. Ao aplicar uma pressão mecânica nesses cristais, ocorre uma deformação de sua estrutura fazendo com que alguns átomos fiquem mais próximos e outros mais distantes, perturbando o balanço entre cargas positivas e negativas, criando uma diferença de potencial (Antunes et al., 2014).

Os materiais com essa característica possuem dois efeitos piezoelétricos, os quais ao serem submetidos a uma pressão ou tensão mecânica geram cargas elétricas em sua superfície, configurando o efeito direto e ao serem submetidos a um campo elétrico, apresentam deformação em sua forma geométrica, representando o efeito inverso. 0 efeito direto é implementado quando se aplica uma força externa e devido ao efeito piezoelétrico gera-se uma tensão. Em seguida, há uma capacitância que é realmente a forma em que ocorre a tensão. A voltagem cresce linearmente com a aplicação de uma força externa. Contudo, a quantidade de energia elétrica não é linear. A Equação 1 apresenta como é calculada a tensão na célula piezoelétrica.

\begin{tabular}{cll} 
& & \multicolumn{1}{c}{$V=\frac{d F t}{\varepsilon_{r} \varepsilon_{0} A}$} \\
em que $\quad V:$ & tensão $[\mathrm{V}] ;$ \\
$d:$ & constante piezoelétrica $[\mathrm{C} / \mathrm{N}] ;$ \\
$t:$ & espessura da célula $[\mathrm{m}] ;$ \\
$F:$ & força externa aplicada $[\mathrm{N}] ;$ \\
$\varepsilon_{r}:$ & constante de permissividade relativa $[\mathrm{F} / \mathrm{m}] ;$ \\
$\varepsilon \varepsilon_{0}:$ & constante de permissividade no vácuo $[\mathrm{F} / \mathrm{m}] ;$ \\
$A:$ & área da superfície da célula $\left[\mathrm{m}^{2}\right]$.
\end{tabular}

Os pavimentos rodoviários são capazes de suportar, ao longo de sua vida útil, uma ampla variedade de cargas, provocando fadiga, tensão, deformação e vibração nas suas camadas, devido à energia transferida da aplicação das cargas dos veículos ao longo de seu deslocamento, fator que contribui diretamente para a perturbação das cargas de sensores piezoelétricos (Zhao et al., 2010). Os autores Cravo (2014), Santos (2014), Duarte e Ferreira (2016) e Papagiannakis et al. (2016) citam a experiência da empresa israelense Innowattech que desenvolveu três sistemas piezoelétricos, materializados em protótipos, para converter a energia mecânica liberada pelos veículos no pavimento em energia elétrica. 0 sistema que apresentou os melhores resultados foi aplicado em ambiente real no ano de 2010. Segundo as pesquisas da empresa Innowattech, com 20 carros passando por uma rodovia por minuto, é possível gerar $200 \mathrm{kWh}$.

Zhao et al. (2014) analisaram a influência das formas geométricas do elemento piezoelétrico titanato zirconato de chumbo (PZT), verificando qual delas geraria o melhor desempenho para uma unidade de captação de energia. Os resultados da análise revelaram que as pilhas de seção transversal circular são preferíveis para maximizar a produção de energia. 
Eles concluíram que se pode ampliar o carregamento aplicado no material para obter mais energia. Os autores estimam que mais de $50 \mathrm{~kW}$ de potência podem ser colhidos a partir de um pavimento asfáltico.

Xiong (2014) desenvolveu um sistema de captação de energia composto por múltiplos elementos piezoelétricos cilíndricos que são ativados pelas cargas do tráfego. Foi verificado que a potência média de saída do captador de energia por veículo é de cerca de 3,20 mW. Com um volume de tráfego de 3.300 veículos por dia esse sistema geraria cerca de 0,36 kWh por ano.

Kim et al. (2015) testaram duas unidades de captação de energia piezoelétrica comercialmente usando um simulador de tráfego. Foram aplicados três níveis de carga a cada coleta de energia ( $222 \mathrm{~N}, 445 \mathrm{~N}$ e $890 \mathrm{~N}$ ) que resultou em tensões variando de 5 a $20 \mathrm{~V}$. Esse experimento foi realizado sob a hipótese de um tráfego de 600 veículos por hora a $72 \mathrm{~km} / \mathrm{h}$, resultando em uma energia de 2,67 mWh.

Moure et al. (2016) testaram algumas cerâmicas piezoelétricas e com os resultados decidiram empregar o Cymbal integrado em segmentos de asfalto, permitindo avaliar a energia elétrica obtida. Cada elemento piezocerâmico recupera até $16 \mu \mathrm{W}$ com a passagem de uma roda de veículo pesado. Esses autores simularam a utilização dos elementos em estradas com alta densidade de veículos, 6.565 veic/h, onde foi identificado que densidades de energia na faixa de 40-50 MWh/m² podem ser obtidas em $100 \mathrm{~m}$ de estrada com a utilização de 30.000 elementos piezoelétricos, o que poderia representar mais de $65 \mathrm{MWh}$ em um ano.

Roshani et al. (2018) desenvolveram dois protótipos com materiais piezoelétricos para analisar as variáveis na geração de energia. 0 protótipo I foi testado com a variação da quantidade de elementos piezoelétricos com 4, 8 ou 16 elementos, além da carga, frequência e temperatura. 0 protótipo II tinha o objetivo de avaliar o efeito da roda móvel na geração de energia em relação à velocidade do tráfego. Além disso, também foram avaliadas as mesmas características do protótipo anterior, com a diferença de que a temperatura e a quantidade de células piezoelétricas serem fixas. Os protótipos I e II chegaram a gerar uma potência de $1.487 \mathrm{~mW}$ e $64,12 \mathrm{~mW}$, respectivamente, quando caminhões trafegavam a $65 \mathrm{~km} / \mathrm{h}$. Quanto aos carros de passeio, a potência gerada se reduz a $33 \mathrm{~mW}$ e 1,36 mW para os protótipos I e II, respectivamente.

Roshani et al. (2018) concluíram que, em uma condição de carga igual, um sistema coletor de energia com um número reduzido de elementos piezoelétricos produzirá uma maior potência. 0 aumento do número de elementos piezoelétricos reduz a tensão aplicada e, consequentemente, reduz a potência gerada por cada elemento individual. Também foi possível constatar que a potência de saída exibe uma correlação positiva com a frequência de carga e velocidade do veículo. Além disso, a potência de saída foi consistente sob carga repetitiva, indicando um baixo risco de deterioração prematura.

A ANTT (2018) propôs a implantação de um sistema piloto que utilizasse transdutores piezoelétricos para o abastecimento de sinalização viária em uma praça de pedágio em Gravataí, município do Rio Grande do Sul. 0 sistema aplicado foi de pequena escala, utilizando apenas 16 transdutores. Com o aumento da quantidade desses sensores seria permitido um aumento da energia gerada. A questão da geração de energia encontrou obstáculo no preço do material, fazendo com que, em princípio, a alternativa não fosse economicamente viável. A potência máxima gerada foi de $36,10 \mu \mathrm{W}$ por veículo.

Após a revisão bibliográfica realizada, observou-se que o tema Energia versus Pavimento foi melhor explorado pelos cientistas nos últimos dez anos e que a tecnologia de geração de energia ainda está em fase de validação nos laboratórios. Verificou-se que a maioria dos estudos não 
possui todos os parâmetros necessários para realizar uma avaliação técnica, econômica e financeira completa. Eles apresentam apenas a capacidade de geração de energia e onde os dispositivos serão instalados. Poucos pesquisadores ou empresas expõem os dados de eficiência de conversão ou de energia captada.

Observou-se que os dados referentes às potências geradas são para velocidades específicas, bem como para pesos de veículos específicos. Outra variável bastante importante é a do fluxo veicular, onde para a Moure et al. (2016) são necessários 6.565 veic/h para gerar o máximo potencial estimado. Algumas pesquisas impossibilitam ainda a reprodução e simulação de quanta energia seria gerada se aplicada em um trecho real, apresentando apenas a quantidade de energia gerada no protótipo testado.

Quanto à instalação dos equipamentos, a maioria é embutida no pavimento entre a camada de revestimento e a camada de base (Zhao et al., 2014; Xiong, 2014; Kim et al., 2015), contudo, não há dados de a qual profundidade eles devem ser instalados. Dessa forma, a influência da carga nos sistemas de captação de energia não maximiza a energia gerada, fato que ocorre apenas quando o sistema é implementado diretamente na superfície do pavimento. Com base na revisão bibliográfica, também foi possível identificar algumas vantagens e desvantagens sobre o tema geração de energia.

As vantagens da utilização da energia mecânica se concentram na questão de não depender de fatores climáticos e possuir uma elevada capacidade de gerar energia (Moure et al., 2016), a depender do tráfego. Destaca-se ainda o fato de já ter sido testada em ambiente real (Cravo, 2014; Santos, 2014; Duarte e Ferreira, 2016; ANTT, 2018) e possuir crescentes testes laboratoriais, podendo as células serem fabricadas a partir de diferentes tipos de materiais, de maneira eficaz e eficiente para maximizar o sistema.

As desvantagens são devidas ao fato de os elementos serem relativamente frágeis, do local de instalação, que pode ter o contato reduzido com o veículo, diminuindo a quantidade de energia gerada e o fato de não abastecer residências sem o armazenamento em geradores de energia (Zhao et al., 2014; Roshani et al., 2018). No entanto, acredita-se que essas desvantagens deverão ser resolvidas nos próximos anos, através de pesquisas nacionais e internacionais relativas ao tema.

Entende-se, diante da revisão bibliográfica realizada, que pesquisas científicas precisam ser incentivadas também na área rodoviária para que o Brasil esteja melhor conectado e preparado para demandas energéticas futuras mais limpas. A melhor solução econômica certamente será encontrada à medida que novos materiais, quiçá até resíduos da produção industrial, e soluções sejam propostas através dos testes de laboratório e campo.

\section{ETAPAS METODOLÓGICAS}

\subsection{Primeira etapa - Realização de análises em software de simulação}

Os métodos utilizados para realização de simulação em sistemas piezoelétricos foram os de autofrequência e de análise estacionária. Na realização das simulações estacionárias e dinâmicas, foi usado o software COMSOL de análises multifísicas para verificar o potencial da geração de energia do material PZT-5H através de um modelo que possibilitasse a aplicação de qualquer carga e velocidade atuante no pavimento conforme parâmetros sugeridos por Roshani et al. (2018). 
As propriedades físicas do material estudado, de acordo com os dados contidos na biblioteca de materiais do software COMSOL, são: (i) densidade do material: $7500 \mathrm{~kg} / \mathrm{m}^{3}$; (ii) constante piezoelétrica d33: 5,93 × 10-10 C/N; (iii) constante de permissividade relativa: $3400 \mathrm{~F} / \mathrm{m}$ e (iv) constante de permissividade no vácuo: $8,85 \times 10^{-12} \mathrm{~F} / \mathrm{m}$.

Sendo assim, nesta análise foram incluídos valores de carga $(1,00 ; 1,50 ; 2,00 ; 2,50 ; 3,00 \mathrm{kN})$ para simular diferentes pesos atuantes no topo da camada de revestimento do pavimento e frequências $(10 \mathrm{~Hz}$ e $20 \mathrm{~Hz}$ ) para analisar distintas velocidades de tráfego correspondentes às velocidades médias usuais de 65 e $130 \mathrm{~km} / \mathrm{h}$, respectivamente. Todo o procedimento efetuado para a análise estacionária e dinâmica junto ao programa computacional encontra-se nos manuais de instruções dos desenvolvedores do software, sendo seguido todo o passo-a-passo (COMSOL, 2015).

\subsubsection{Análise estacionária}

Foi realizada uma análise estacionária, com sete geometrias de células piezoelétricas diferentes, com o objetivo de se obter a propriedade geométrica mais significativa para a geração do potencial elétrico máximo no pavimento. A seleção de geometrias diferentes foi realizada para se verificar o quanto a duplicação ou redução da área e da espessura influenciam no potencial elétrico máximo gerado e no estresse ao qual a célula é submetida. 0 material analisado foi o PZT$5 \mathrm{H}$ em todas as células, que de acordo com Zhao et al. (2014) e Roshani et al. (2018) é tido como um dos mais resistentes e de elevada capacidade elétrica.

As geometrias testadas foram: (i) Retangular 1 (R1) com largura de 1,50 mm, comprimento de 3,00 mm e espessura de 0,40 mm; (ii) Retangular 2 (R2) com largura de 2,25 mm, comprimento de 4,00 mm e espessura de 0,40 mm; (iii) Retangular 3 (R3) com largura de 1,50 mm, comprimento de 3,00 mm e espessura de 0,80 mm; (iv) Retangular 4 (R4) com largura de 2,25 $\mathrm{mm}$, comprimento de 4,00 mm e espessura de 0,80 mm; (v) Circular 1 (C1) com raio de 1,20 mm e espessura de 0,40 mm; (vi) Circular 2 (C2) com raio de 4,28 mm e espessura de 6,20 mm e (vii) Circular 3 (C3) com raio de 6,05 mm e espessura de 3,10 mm. Na Figura 1 estão representadas essas estruturas.

(a)

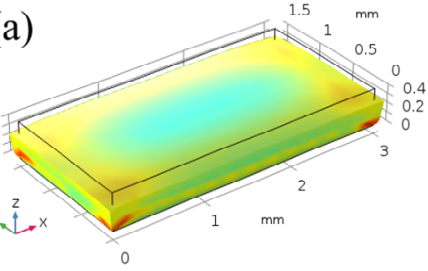

(d)

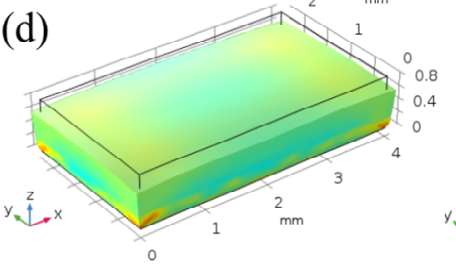

(g)

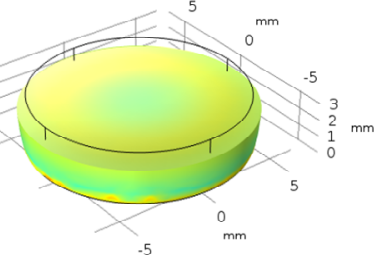

(b)

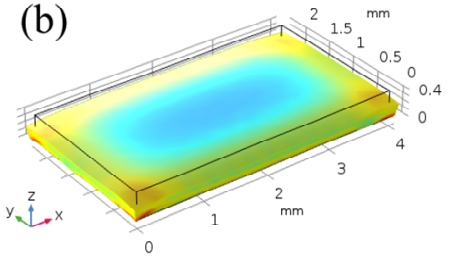

(e)

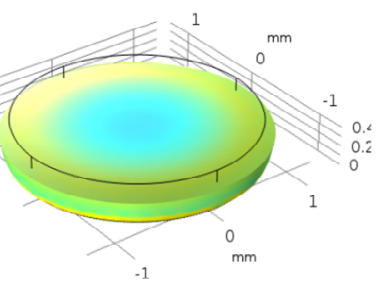

(c)

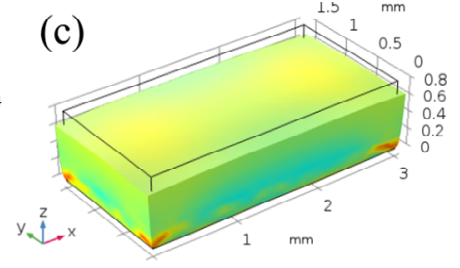

(f)

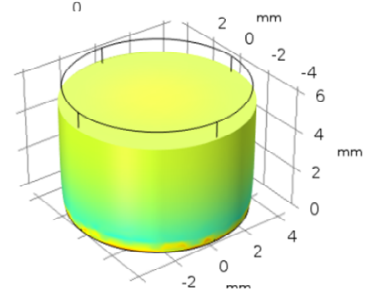

Figura 1. Geometria das células testadas $(a-R 1, b-R 2, c-R 3, d-R 4, e-C 1, f-C 2$ e $g-C 3)$ 


\subsubsection{Análise dinâmica}

Para a análise dinâmica foram consideradas apenas duas geometrias (R1 e C2), que foram escolhidas em razão da necessidade de comparação entre a saída elétrica e a mudança de forma dos elementos. Nesta etapa foram consideradas 4 células de cada geometria analisada entre duas placas de cobre. A análise dinâmica foi realizada de forma a simular a atuação do veículo em movimento, devido às frequências $(10 \mathrm{~Hz}$ e $20 \mathrm{~Hz})$ emitidas os pesos distribuídos linearmente, para verificar a influência da carga na geração de energia $(1,0 \mathrm{kN}, 1,5 \mathrm{kN}, 2,0 \mathrm{kN}, 2,5 \mathrm{kN}$, $3,0 \mathrm{kN}$ ). É válido considerar que com base no teorema da transferência de potência máxima, a resistência externa no circuito deve ser igual à resistência interna do protótipo para obter a potência máxima, definida como correspondência de impedância. A resistência interna do protótipo foi calculada pela Equação 2, considerando a quantidade de células piezoelétricas inseridas no protótipo.

\begin{tabular}{|c|c|c|}
\hline \multirow[b]{2}{*}{ em que } & \multicolumn{2}{|r|}{$R_{S}=\frac{1}{2 \pi c f}$} \\
\hline & $R_{S}:$ & resistência interna $[\Omega]$; \\
\hline & $c:$ & capacitância interna do protótipo $[\mathrm{F}]$; \\
\hline & $f:$ & carga de pulso por segundos [Hz]. \\
\hline
\end{tabular}

\subsection{Segunda etapa - Proposição do protótipo}

Após as análises, foi proposto um protótipo de geração de energia piezoelétrica, aplicado no topo da camada de revestimento, com as relações obtidas entre a carga e a quantidade de potência gerada. Devido a essas estruturas precisarem ser implementadas a uma determinada espessura abaixo do revestimento, certamente resultará em uma redução da potência gerada e aqui obtida. Dessa forma, foram utilizadas cargas reais atuantes no pavimento rodoviário, como 1,98 kN para uma roda de veículo normal de passeio e 24,50 kN para uma roda de caminhão, com eixo simples típico, conforme sugestões de Yoder e Witczak (1975), Medina e Motta (2015) e a resolução no 210 do Conselho Nacional de Trânsito (CONTRAN, 2006).

As células piezoelétricas foram posicionadas entre duas placas de cobres quadradas, possuindo $10 \mathrm{~cm}$ de lado e $6 \mathrm{~mm}$ de espessura. No protótipo, o cobre atua como condutor da propriedade dielétrica pertencente ao material piezoelétrico para o sistema de captação de energia a ser implantado no pavimento. A Figura 2, a título de exemplo, representa o arranjo das células entre as placas de cobre.

(a)

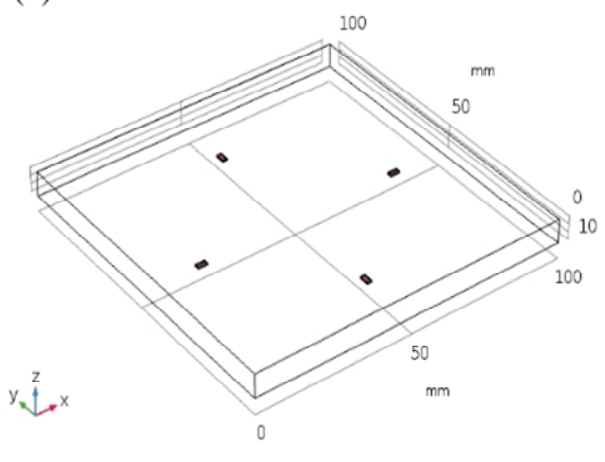

(b)

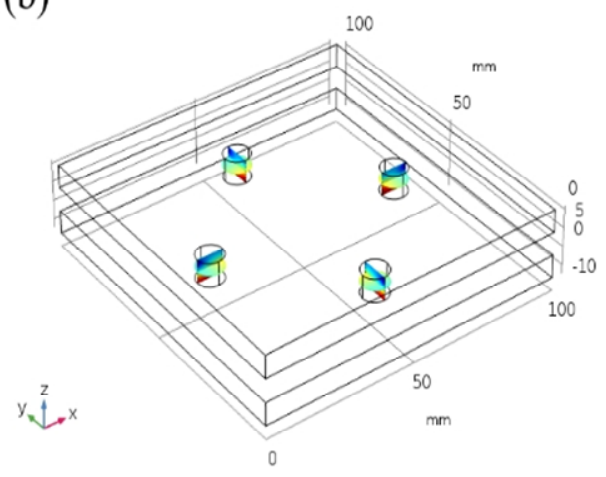

Figura 2. Arranjo das células de geometria diferentes ( $\mathrm{a}$ - R1 e b - C2) 
A análise realizada baseou-se na efetuada por Roshani et al. (2018), na qual avaliou-se a capacidade de produção de energia elétrica a partir do protótipo proposto. Os valores de potência apresentados na seção de resultados para a frequência de $10 \mathrm{~Hz}$, simulados no COMSOL e, que também podem ser representados pela Equação (3), foram utilizados para a simulação desta etapa.

$$
y=2,62 x^{2}-0,046 x+0,038
$$

em que $y$ :

saída de potência elétrica $[\mathrm{mW}]$;

$x: \quad$ carga aplicada $[\mathrm{kN}]$;

A composição do volume de tráfego utilizada como entrada na análise de produção da potência foi: (i) extensão da via: $1 \mathrm{~km}$; (ii) velocidade de tráfego: $65 \mathrm{~km} / \mathrm{h}$; (iii) volume médio diário (VMD): 600 veículos/dia; (iv) número de faixas: 4; (v) divisão direcional: 50/50; (vi) porcentagem de carros: 70 \%; (vii) porcentagem de caminhões: 30 \%; (viii) pneus de carros e caminhões pesando 1,98 kN e 24,50 kN, respectivamente; (ix) cargas inteiras dos pneus foram transmitidas aos elementos piezoelétricos e $(\mathrm{x})$ para os caminhões com eixo simples típico, com a área de contato do pneu de aproximadamente $355 \mathrm{~cm}^{2}$, foi realizada uma proporção de absorção da energia gerada por protótipo, igual a $28,17 \%$ da carga aplicada.

É necessário destacar aqui as limitações das simulações, tanto na análise estacionária quanto na dinâmica, bem como para as estruturas de cobre testadas. A adoção de fio terra apenas na parte inferior da célula e o potencial flutuante na face superior da célula podem limitar a análise, incluindo a fixação de uma face. É válido ressaltar que a aplicação das cargas foi realizada diretamente na placa de cobre ou na célula piezoelétrica, em apenas um ponto central da estrutura, por razões do baixo processador da máquina em que se encontrava instalado o software.

\section{ANÁLISE E DISCUSSÃO DOS RESULTADOS}

\subsection{Primeira etapa - Realização de análises em software de simulação}

\subsubsection{Simulação estacionária}

As tensões foram obtidas no software de análise multifísica após o processamento de cada uma das simulações. Toda estrutura simulada gerou o estresse devido ao carregamento em $\mathrm{MN} / \mathrm{m}^{2}$ e a tensão na configuração da célula em volts (V) durante a etapa estacionária. A Tabela 1 apresenta os resultados relativos ao estresse máximo e mínimo sofridos pelas células. Na Figura 3 é possível analisar a tensão quanto à forma geométrica da célula piezoelétrica.

A célula $\mathrm{C} 1$ foi projetada para possuir mesma área e mesma espessura que a célula $\mathrm{R} 1$, tanto que se observa uma sobreposição das retas correspondentes a tensão delas. Porém, a sensibilidade do software não permitiu analisar áreas exatamente iguais, havendo uma diferença de $0,0005 \%$, ficando a célula C1 um pouco maior que a R1. Há uma pequena redução na tensão máxima, de aproximadamente 0,5 \%. 0 estresse mínimo sofreu redução e o máximo sofreu aumento, o que prejudica a estrutura da célula, visto que houve crescimento na amplitude do estresse, possibilitando uma menor vida útil às células.

Em cada uma das células retangulares derivadas da primeira (R1) e na C1 foi analisado o quanto havia de redução no estresse e na tensão em decorrência do aumento da espessura ou da área. Em linhas gerais, foi possível observar que as células R3 e R4 apresentaram maior crescimento na tensão em relação à R1. As células R2 e C1 apresentaram redução na tensão quando comparadas à R1. 
Tabela 1 - Seleção das empresas para estudo e respectiva frota, por tipo de motor

\begin{tabular}{|c|c|c|c|c|c|c|c|c|c|c|c|c|c|}
\hline & \multirow{3}{*}{$\begin{array}{c}\text { Carga } \\
\text { (kN) }\end{array}$} & \multicolumn{12}{|c|}{ Geometrias } \\
\hline & & \multirow{2}{*}{ R1 } & \multicolumn{2}{|c|}{ R2 } & \multicolumn{2}{|c|}{ R3 } & \multicolumn{2}{|c|}{ R4 } & \multicolumn{2}{|c|}{ C1 } & \multirow{2}{*}{$\mathrm{C} 2$} & \multicolumn{2}{|c|}{ C3 } \\
\hline & & & V & Red & V & Red & V & Red & V & Red & & V & Red \\
\hline \multirow{5}{*}{ 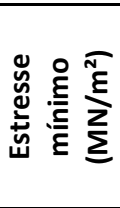 } & 1,0 & 130 & 62 & 52 & 130 & 0 & 66 & 49 & 123 & 5 & 10 & 5,0 & 51 \\
\hline & 1,5 & 195 & 96 & 51 & 195 & 0 & 100 & 49 & 190 & 3 & 15 & 7,5 & 50 \\
\hline & 2,0 & 260 & 125 & 52 & 260 & 0 & 133 & 49 & 252 & 3 & 20 & 9,8 & 51 \\
\hline & 2,5 & 325 & 158 & 51 & 325 & 0 & 162 & 50 & 310 & 5 & 25 & 12,1 & 52 \\
\hline & 3,0 & 390 & 190 & 51 & 390 & 0 & 200 & 49 & 380 & 3 & 30 & 16,0 & 47 \\
\hline \multirow{5}{*}{ 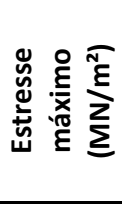 } & 1,0 & 270 & 133 & 51 & 288 & -7 & 150 & 44 & 286 & -6 & 22 & 11,2 & 49 \\
\hline & 1,5 & 405 & 201 & 50 & 440 & -9 & 225 & 44 & 440 & -9 & 33 & 17,0 & 48 \\
\hline & 2,0 & 540 & 267 & 51 & 575 & -6 & 300 & 44 & 570 & -6 & 44 & 22,5 & 49 \\
\hline & 2,5 & 675 & 338 & 50 & 720 & -7 & 378 & 44 & 715 & -6 & 55 & 28,3 & 49 \\
\hline & 3,0 & 809 & 401 & 50 & 870 & -8 & 450 & 44 & 857 & -6 & 66 & 34,0 & 48 \\
\hline 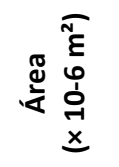 & & 4,5 & \multicolumn{2}{|c|}{9,0} & \multicolumn{2}{|c|}{4,5} & \multicolumn{2}{|c|}{9,0} & \multicolumn{2}{|c|}{4,5} & 57,5 & \multicolumn{2}{|c|}{115,0} \\
\hline
\end{tabular}

Legenda: Red (redução) em \% e V (valor).

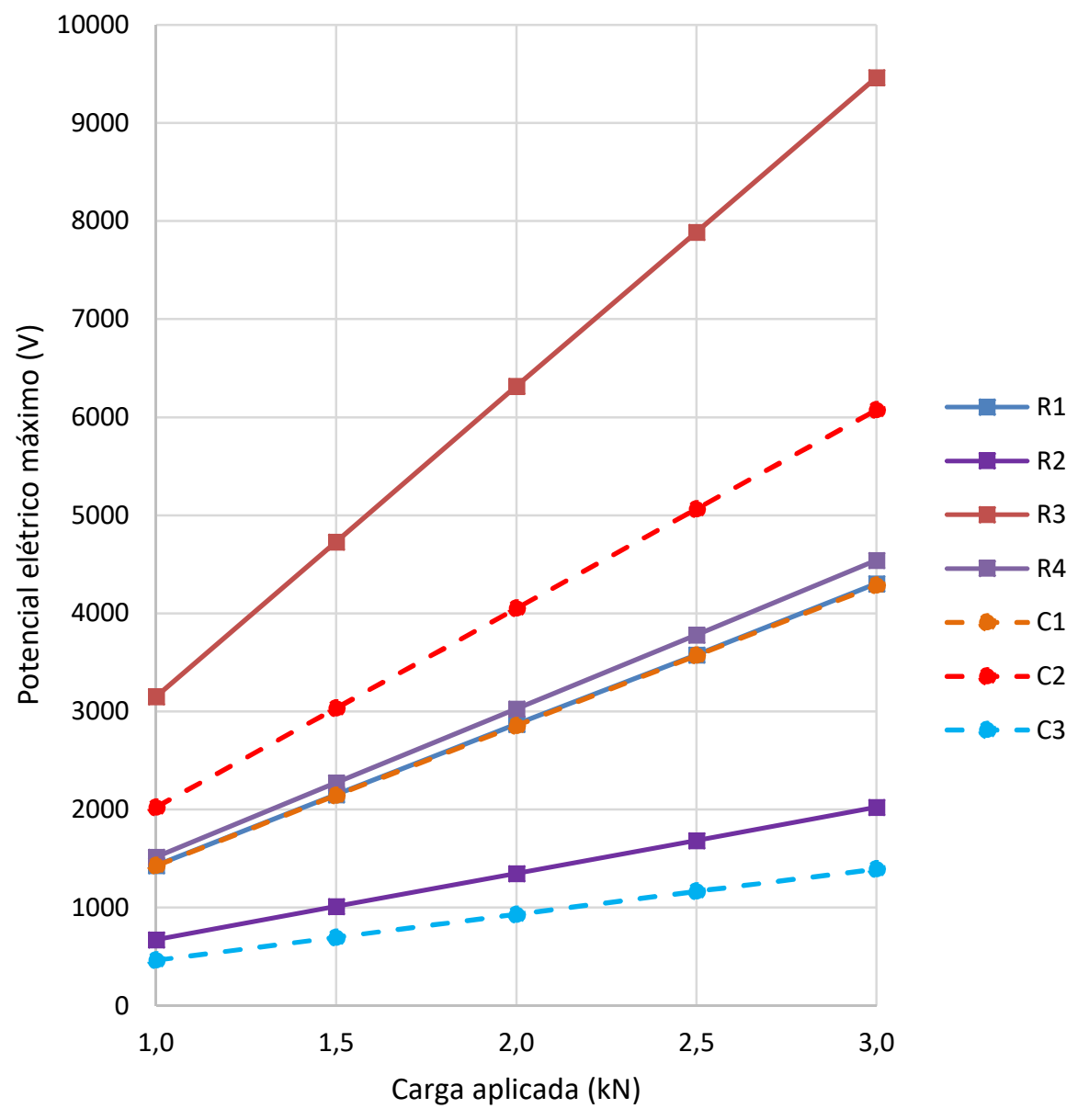

Figura 3. Tensão máxima estacionária

Quando o estresse é analisado se percebe que apenas no estresse máximo das células R3 e C1 ocorre aumento. Ao analisar a célula C3, derivada da C2, percebe-se uma elevada redução da tensão. Os valores negativos apresentados na Tabela 1 simbolizam um aumento na variável analisada quando comparada à célula de referência. 
Na Tabela 2 são apresentados os valores da tensão obtidos pelo software e os obtidos pela Equação 1, apresentada no corpo deste trabalho. É possível perceber que os valores de tensão das simulações ficam próximos aos encontrados com a aplicação da Equação 1. A diferença é devida as limitações impostas pela modelagem, que foram apresentadas na seção de métodos. É válido ressaltar que esses valores de tensão são referentes à capacidade máxima de geração da célula e que os mesmos mudarão de acordo com as propriedades do material (PZT-4, PZT-5A, PZT-5H, etc), de acordo com a espessura da célula e a posição em que a carga é aplicada sobre a mesma.

Neste trabalho a carga é aplicada diretamente sobre a célula piezoelétrica isolada, o que eleva a tensão gerada. Contudo, a carga aplicada diretamente sobre a célula resultaria na fragmentação precoce da mesma. Autores como Papagiannakis et al. (2016) e Roshani et al. (2018) encontram valores reduzidos de tensão devido a configuração de seus protótipos e a posição de aplicação da carga neles, já simulando a situação em campo. Essa análise teórica foi realizada, exclusivamente, para verificar a influência das propriedades geométricas no valor da tensão.

Tabela 2 - Valores de tensão pelo software e pela equação 1

\begin{tabular}{|c|c|c|c|c|c|c|c|c|c|c|c|c|c|c|}
\hline \multirow{3}{*}{$\begin{array}{c}F \\
k N\end{array}$} & \multicolumn{14}{|c|}{ Tensão (V) } \\
\hline & \multicolumn{2}{|c|}{ R1 } & \multicolumn{2}{|c|}{ R2 } & \multicolumn{2}{|c|}{ R3 } & \multicolumn{2}{|c|}{ R4 } & \multicolumn{2}{|c|}{ C1 } & \multicolumn{2}{|c|}{ C2 } & \multicolumn{2}{|c|}{ C3 } \\
\hline & $\mathbf{S}$ & 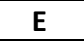 & $S$ & $\mathbf{E}$ & $\mathbf{S}$ & $\mathrm{E}$ & $\mathbf{S}$ & $E$ & $\mathrm{~S}$ & $\mathbf{E}$ & $\mathrm{S}$ & E & $S$ & $E$ \\
\hline 1,0 & 1430 & 1752 & 675 & 876 & 3152 & 3504 & 1517 & 1752 & 1430 & 1752 & 2025 & 2125 & 466 & 531 \\
\hline 1,5 & 2155 & 2628 & 1015 & 1314 & 4730 & 5255 & 2275 & 2628 & 2146 & 2628 & 3037 & 3187 & 698 & 797 \\
\hline 2,0 & 2870 & 3504 & 1349 & 1752 & 6317 & 7007 & 3027 & 3504 & 2857 & 3504 & 4053 & 4250 & 932 & 1062 \\
\hline 2,5 & 3580 & 4379 & 1685 & 2190 & 7888 & 8759 & 3783 & 4379 & 3573 & 4379 & 5067 & 5312 & 1168 & 1328 \\
\hline 3,0 & 4305 & 5255 & 2023 & 2628 & 9467 & 10511 & 4543 & 5255 & 4287 & 5255 & 6077 & 6375 & 1395 & 1594 \\
\hline
\end{tabular}

Pode-se constatar que ao duplicar a área das células piezoelétricas, a tensão sofre uma redução de 53 \%, apesar de ter uma relação proporcional com a espessura. Quando a espessura é duplicada, o valor da tensão é elevado em aproximadamente $120 \%$. Quando ocorre a duplicação de ambas as propriedades, mesmo mantendo as mesmas proporções da célula de referência, a tensão apresenta um aumento de aproximadamente $6 \%$. Além disso, foi possível observar que houve uma redução de $77 \%$ da tensão quando a espessura foi reduzida pela metade e a área duplicada na célula C3.

Percebe-se, através desta análise, que a espessura da célula piezoelétrica é a propriedade geométrica que mais influencia na tensão. A Equação 1, exposta na sessão de revisão, já permitia supor essa constatação, visto a espessura encontrar-se na parte superior da equação. Contudo, a partir das análises realizadas, foi possível ver que a relação entre a espessura e a área não é totalmente proporcional, ocasionando um aumento mais significativo da tensão quando a espessura é elevada, comparando-se a mesma modificação, em termos de proporção, com a área da célula, o que resulta em um impacto menor na redução da tensão.

De acordo com o apresentado na Tabela 1 foi possível também perceber que quando a área é ampliada, o estresse na célula reduz acima de $50 \%$ para todas as células piezoelétricas, o que possibilita que as pressões se distribuam de forma mais equilibrada, sem trazer danos a sua estrutura. Quando a área é mantida igual e a espessura é duplicada, o estresse mínimo permanece igual em todas as células, contudo, o estresse máximo é ampliado em aproximadamente $7 \%$. Assim, pode-se dizer que uma elevada área possibilita menos dano à célula piezoelétrica e que a espessura possibilita um pequeno aumento no estresse máximo. 
É necessária uma avaliação para verificar o quanto seria benéfico aumentar a espessura para elevar o potencial elétrico, mas sem causar danos à estrutura devido a esse aumento no estresse.

\subsubsection{Simulação dinâmica}

Para a análise dinâmica foram avaliadas duas geometrias disponíveis comercialmente (R1 e C2), para verificar a possibilidade de implementação em um trecho experimental. Ao agrupar as células piezoelétricas em um protótipo, o potencial elétrico do sistema foi reduzido, devido ao aumento da área de atuação da carga. É válido ressaltar que a área de atuação é considerada apenas a área conjunta das células piezoelétricas (4 elementos), pois a placa de cobre serve apenas para conduzir a eletricidade. Além disso, há a influência das frequências de $10 \mathrm{~Hz}$ e 20 $\mathrm{Hz}$ combinadas com a atuação da carga e o fato de a mesma não ser aplicada diretamente na célula. Roshani et al. (2018) ressaltam que a posição da célula piezoelétrica no protótipo também influencia na quantidade de energia gerada.

Para essa análise, foram calculadas as resistências dos protótipos, conforme a Equação 2, resultando em: 11,75 M $\Omega$ e 14,25 M $\Omega$ para a configuração com a célula R1 e com a célula C2, respectivamente. A Figura 4 apresenta a relação da aplicação da carga com a potência para a combinação de 4 células entre duas placas de cobre, que servem de condutoras, para as frequências de $10 \mathrm{~Hz}$ e $20 \mathrm{~Hz}$.

A Figura 4 permite realizar a análise para as duas frequências mais atuantes no pavimento rodoviário, de $10 \mathrm{~Hz}$ e $20 \mathrm{~Hz}$, devido ao elevado coeficiente de correlação obtido em todas as simulações testadas. Conforme ilustrado, aumentar a magnitude da carga está associado ao aumento da potência.
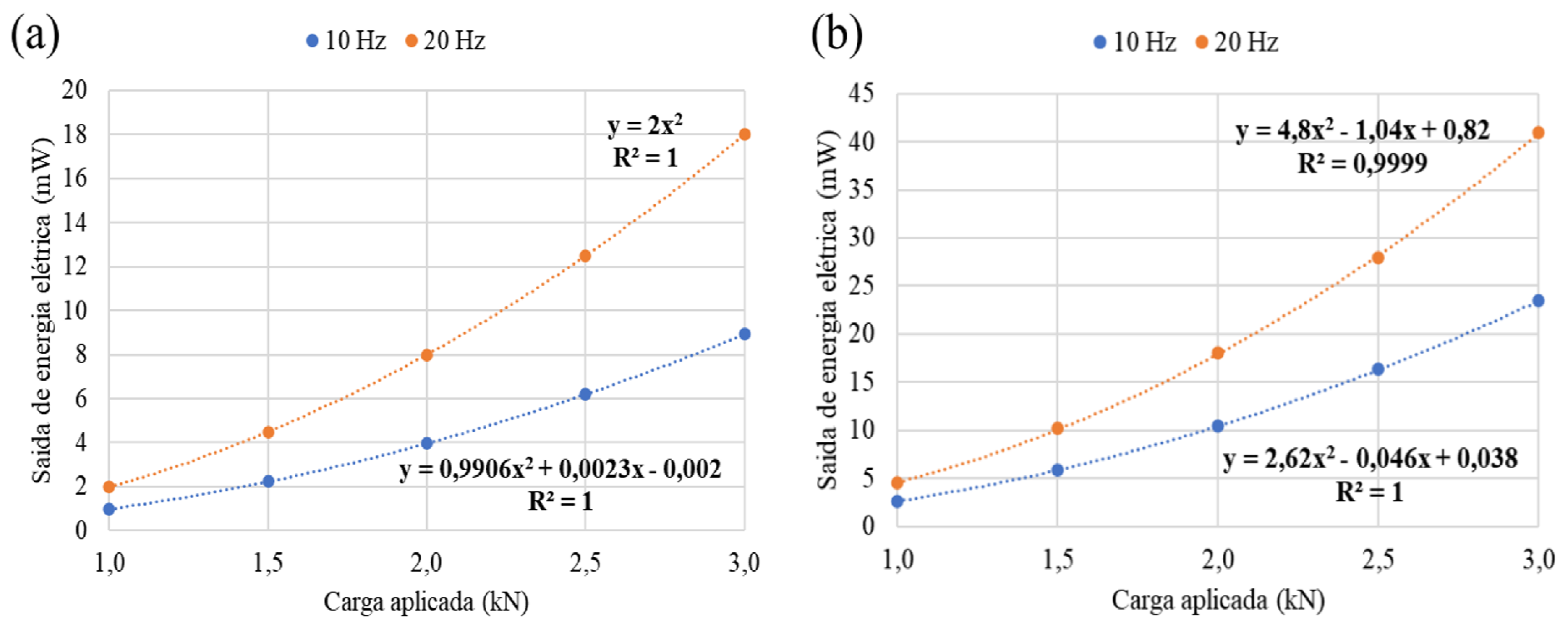

Figura 4. Potência gerada para as células de geometria diferentes ( $a$ - R1 e b - C2)

Com a variação da aplicação das frequências, e o aumento da carga, é notado um incremento na potência. Também é perceptível que quando aplicada uma frequência maior, a defasagem entre frequências tende a acontecer de forma exponencial, conforme a variação de carga. Essa análise permite avaliar que as células piezoelétricas têm uma resposta elétrica maior com frequências elevadas, pois o aumento delas reduz o tempo de carregamento nas células piezoelétricas. Pela Figura 4 é notória a capacidade de resposta da potência gerada. 
Para uma carga de $3 \mathrm{kN}$ e uma frequência de $20 \mathrm{~Hz}$, a combinação das quatro células circulares 2 chegam a responder mais de $40 \mathrm{~mW}$.

Contudo, em razão da carga máxima simulada ter sido menor que $13 \%$ da carga de $24,50 \mathrm{kN}$, optou-se por simulá-la diretamente no software. 0 mesmo foi feito para a carga de $1,98 \mathrm{kN}$. Dessa forma, para as células R1, a força aplicada por um único pneu de automóvel resultou em 3,88 mW para $10 \mathrm{~Hz}$ e 7,84 mW para $20 \mathrm{~Hz}$, enquanto que a de um caminhão de eixo simples típico resultou em 594,5 mW e $1.200 \mathrm{~mW}$ para $10 \mathrm{~Hz}$ e $20 \mathrm{~Hz}$, respectivamente. Enquanto que para as células C2, esses valores foram de 10,20 mW para $10 \mathrm{~Hz}$ e 17,55 mW para $20 \mathrm{~Hz}$ quando submetidas a $1,98 \mathrm{kN}$ e de $1.570 \mathrm{~mW}$ para $10 \mathrm{~Hz}$ e $2.730 \mathrm{~mW}$ para $20 \mathrm{~Hz}$ quando aplicada a força de $24,50 \mathrm{kN}$. A maior diferença quando comparados os valores das simulações aos obtidos pelas equações presentes na Figura 4 foi de $4,43 \%$, para a última situação mencionada (célula C2, carga de $24,50 \mathrm{kN}$ e frequência de $20 \mathrm{~Hz}$ ), explicada, principalmente, pelo $\mathrm{R}^{2}$ de 0,99 .

Esses resultados auxiliam na determinação de potenciais locais para instalação desses protótipos com células piezoelétricas. Pode-se sugerir, desse modo, que trechos de rodovias interestaduais com alta velocidade e volume de tráfego, bem como vias expressas, possam ser bons candidatos. Contudo, se implementado em locais com grande fluxo de carros, mas com elevados índices de congestionamento, acrescentando ainda áreas de estacionamento e cruzamentos controlados por sinais de trânsito, essa eficiência pode ser reduzida, visto que os veículos estarão com velocidade tendendo a zero, aliado ainda ao maior tempo de carregamento.

Também é necessária uma avaliação da resistência externa do protótipo. Foi verificado que ao passo que a resistência externa do protótipo se distancia, para mais ou para menos, da resistência interna calculada, a quantidade de energia gerada diminui. Quando a resistência externa é igual a interna, a potência é máxima, com valores iguais aos apresentados na Figura 4.

\subsection{Segunda etapa - Proposição do protótipo}

Diante das análises realizadas, foram selecionadas as células de geometria C2, tanto pela sua disponibilidade em mercado quanto pela sua resposta elétrica elevada, para simulação de aplicação em um trecho ideal de rodovia. A Tabela 3 mostra a produção de potência por um protótipo coletor de energia, composto por 4 células piezoelétricas cada, para a composição de tráfego assumida anteriormente. Os valores encontrados são em watt (W), sendo necessária uma análise de dependência do tempo para verificar a produção em watt-hora. Ressaltando, ainda, que foram adotados os valores encontrados pelas simulações realizadas no COMSOL.

Tabela 3 - Produção de potência

\begin{tabular}{lll}
\hline Tipos de Pneus & Potência gerada & Unidade \\
\hline Pneu de carro/módulo & 0,0102 & $\mathrm{~W}$ \\
Pneu de caminhão/módulo & 0,4422 & $\mathrm{~W}$ \\
Pneu de carros/dia/módulo & 4,2840 & $\mathrm{~W}$ \\
Pneu de caminhões/dia/módulo & 79,5960 & $\mathrm{~W}$ \\
Pneu de carros/ano/módulo & 1,5647 & $\mathrm{~kW}$ \\
Pneu de caminhões/ano/módulo & 29,0724 & $\mathrm{~kW}$ \\
\hline
\end{tabular}

Para uma rodovia de $1 \mathrm{~km}$, poderiam ser instalados 10.000 protótipos de $10 \mathrm{~cm} \times 10 \mathrm{~cm}$, com espaçamento de $10 \mathrm{~cm}$ entre eles, nos bordos da rodovia, totalizando 5.000 em cada. Para essa implementação, seriam necessárias 40.000 células piezoelétricas da geometria circular 2 . 
O custo de fabricação desses módulos, por consultas de preços de materiais disponíveis em maio de 2020, girou em torno de $\mathrm{R} \$ 470,00 /$ protótipo, considerando apenas as placas de cobre e as células piezoelétricas. Para $1 \mathrm{~km}$ de rodovia, esse valor seria estimado em $\mathrm{R} \$ 4.700 .000,00$ sendo considerado apenas o valor das células e das placas de cobre, com a implementação em toda a extensão dos bordos da rodovia.

A priori, o custo pode ser elevado, contudo, com a resposta elétrica possivelmente gerada e armazenada, o mesmo pode ser compensado. Essa análise deve ser realizada com minuciosidade, verificando ainda como se daria o processo de instalação, manutenção e reparação desse sistema quando integrado ao pavimento.

Pode-se observar que um protótipo, formado 4 elementos piezoelétricos, poderia produzir 30,6371 kW de potência por ano, considerando o tráfego ora supracitado, resultando em 306,3710 MW com a instalação dos 10.000 protótipos, que durante uma vida útil de 10 anos se traduz em 3,0637 GW. De acordo com dados da EPE (2018), o consumo médio anual de energia elétrica de uma residência no Ceará é de 1.915,80 kWh. Dessa forma, com a instalação dos protótipos ao longo de $1 \mathrm{~km}$ de rodovia, seria possível abastecer aproximadamente 160 domicílios, considerando que a potência não varie com o tempo.

No Ceará, de acordo com dados da companhia de distribuição de energia elétrica, o preço do $\mathrm{kWh}$ médio é de $\mathrm{R} \$ 0,597$. Logo, em um ano, cada domicílio gasta, aproximadamente, em média $\mathrm{R} \$ 1.200,00$. Dessa forma, com a quantidade possível de domicílios em $1 \mathrm{~km}$, o custo de energia seria em torno de $\mathrm{R} \$ 192.000,00$, o que em cerca de 24,5 anos traria retorno financeiro relativo ao gasto de materiais, considerando o investimento apontado com a aquisição do cobre e das células piezoelétricas. Para esse cálculo não foram considerados, por falta de informações disponíveis na literatura, os custos de instalação e manutenção do sistema.

\section{CONSIDERAÇÕES FINAIS}

A principal contribuição deste trabalho está centrada nas simulações realizadas que forneceram parâmetros para identificação da espessura como a propriedade geométrica que mais influência na resposta elétrica, visto que, ao duplicar a espessura, há um aumento de $120 \%$ na tensão gerada, enquanto que ao dobrar a área das células, há uma redução de 53 \% da sua tensão. Essa análise permite uma concepção de estrutura da célula piezoelétrica mais ideal, centrada em uma maior espessura. Também foi possível constatar que a geometria circular gera uma redução do potencial elétrico quando comparada à geometria retangular, o que contrapõe o exposto por Roshani et al. (2018), em que dizem que a circular fornece uma resposta elétrica maior.

A partir das simulações dinâmicas foi possível constatar que há um ganho na quantidade de potência gerada com o aumento da frequência, sendo a saída elétrica quase duplicada com a mudança de $10 \mathrm{~Hz}$ para $20 \mathrm{~Hz}$, na medida que a força também cresce, em que para $3 \mathrm{kN}$, a saída elétrica passa de $23 \mathrm{~mW}$ para $40 \mathrm{~mW}$. Dessa forma, sendo possível concluir que a quantidade de energia está condicionada ao tráfego existente na via, a espessura das células piezoelétricas, a velocidade dos veículos e a magnitude da carga transmitida a elas. Para as situações abordadas neste artigo, a quantidade máxima acumulada de potência durante a vida útil de projeto da rodovia seria de 3,0637 GW.

A sucinta análise financeira de aquisição do custo de materiais permitiu observar que, para as condições de instalação propostas, o sistema não é vantajoso, sendo necessário aproximadamente 25 anos para haver um retorno financeiro, sem considerar custos de instalação e manutenção do sistema. Contudo, espera-se que com a realização de mais pesquisas na área, 
as variáveis que influenciam a quantidade de energia gerada sejam otimizadas a fim de fornecer um retorno financeiro mais rápido, permitindo a utilização da piezoeletricidade como alternativa complementar ao sistema de abastecimento elétrico de uma região. Sendo possível, então, a alimentação de residências ou, a priori, instrumentos da própria via, como por exemplo a sua iluminação, o controle de semáforos e, futuramente, o autoabastecimento de veículos elétricos, possibilitando um sistema autônomo e eficiente de geração de energia.

\section{AGRADECIMENTOS}

Os autores agradecem ao CNPq pela bolsa de mestrado do primeiro autor, à Petrobras pelo financiamento da pesquisa na área de energia e ao Laboratório de Telecomunicações e Ciência e Engenharia de Materiais pela concessão da licença do software COMSOL.

\section{REFERÊNCIAS}

ANTT (2018) Estratégias de eficiência energética em praças de pedágio rodoviário. Relatório Final de Pesquisa RDT, Agência Nacional de Transportes Terrestres, Triunfo | CONCEPA. Disponível em: <https://bityli.com/w2bj0>. (Acesso em 16/08/2021).

Andriopoulou, S. A. (2012) Review on energy harvesting from roads. Dissertação (mestrado). Faculdade de Arquitetura, Ciência do Transporte, Estradas e Engenharia Ferroviária, KTH Royal Institute of Technology. Suécia.

Antunes, E. de G.; M. N. de Sousa e M. N. da C. Schertel (2014) Piso que transforma energia mecânica em eletricidade. Universidade Federal do Rio Grande do Sul. Disponível em: < http://www.ufrgs.br/projenergia3/projetos/trabalhos-2014/trabalhos-2014-2/GRUPOH.pdf>. (Acesso em 18/01/2021).

CEARÁ (2010) Atlas Solarimétrico do Ceará. Fundação Cearense de Meteorologia e Recursos Hídricos - Funceme (Org.), Fortaleza.

CEARÁ (2018a) Estudo de Tendências de Longo Prazo: Ceará 2050. Estudos de Megatendências da Ey. Governo do Estado do Ceará.

CEARÁ (2018b) Projeto Ceará 2050 estudo setorial especial: recursos naturais e ecologia. Governo do Estado do Ceará.

COMSOL (2015) Optimizing the Power of a Piezoelectric Energy Harvester. Disponível em: <https://br.comsol.com/blogs/optimizing-the-power-of-a-piezoelectric-energy-harvester/>. (Acesso em 18/01/2021).

CONTRAN (2006) Resolução no 210: limites de peso e dimensões para veículos que transitem por vias terrestres. Ministério das Cidades. Disponível em: <https://www.camara.leg.br/proposicoesWeb/prop_mostrarintegra?codteor=1608786>. (Acesso em 16/08/2021).

Cravo, L. da S. (2014) Geração de Energia nos Pavimentos Rodoviários. Dissertação (mestrado). Universidade de Coimbra, Coimbra.

Duarte, F. e A. Ferreira (2016) Sistema de geração de energia elétrica nos pavimentos rodoviários. Anais do 8o Congresso rodoviário português, Lisboa, p. 1-10.

Elkington, J. (1999) Cannibals with forks. New Society, Canadá.

EPE (2018) Consumo Anual de Energia Elétrica por classe. Empresa de Pesquisa Energética. Disponível em: <http://www.epe.gov.br/pt/publicacoes-dados-abertos/publicacoes/Consumo-Anual-de-Energia-Eletrica-por-classenacional $\geq$. (Acesso em 18/01/2021).

EPE (2019) Balanço Energético Nacional 2019: Ano base 2018. Empresa de Pesquisa Energética, Rio de Janeiro.

Kim, S.; J. Shen e M. Ahad (2015) Piezoelectric-Based Energy Harvesting Technology for Roadway Sustainability. International Journal of Applied Science and Technology, v. 5, n. 1, p. 20-25. Disponível em: <http://www.ijastnet.com/journals/Vol_5_No_1_February_2015/3.pdf>. (Acesso em 18/01/2021).

Medina, J. e L. M. G. da Motta (2015) Mecânica dos pavimentos (3 $3^{\mathrm{a}}$ ed.). Interciência, Rio de Janeiro.

Moure, A.; M. A. I. Rodríguez; S. H. Rueda; A. Gonzalo; F. R. Marcos; D. U. Cuadros; A. Pérez-Lepe e J. F. Fernández (2016) Feasible integration in asphalt of piezoelectric cymbals for vibration energy harvesting. Energy Conversion and Management, v. 112, p. 246-253. DOI: 10.1016/j.enconman.2016.01.030

Papagiannakis, A. T.; S. Dessouky; A. Montoya e H. Roshani (2016) Energy Harvesting from Roadways. Procedia Computer Science, v. 83, p.758-765. DOI: 10.1016/j.procs.2016.04.164

Roshani, H.; P. Jagtap; S. Dessouky; A. Montoya e A. T. Papagiannakis (2018) Theoretical and Experimental Evaluation of Two Roadway Piezoelectric-Based Energy Harvesting Prototypes. Journal of Materials in Civil Engineering, v. 30, n. 2, p.04017264-04017264. DOI: 10.1061/(ASCE)MT.1943-5533.0002112

Santos, V. C. (2014) Aplicação de Sistemas de Geração de Energia nos Pavimentos Rodoviários. Dissertação (mestrado). Universidade de Coimbra, Coimbra. Disponível em: <https://estudogeral.uc.pt/bitstream/10316/38607/1/Aplicaсао $\% 20 \mathrm{de} \% 20$ sistemas\%20de\%20geracao\%20de\%20energia\%20nos\%20pavimentos\%20rodoviarios.pdf> (Acesso em $16 / 08 / 2021)$

Xiong, H. (2014) Piezoelectric Energy Harvesting for Public Roadways. Dissertação (mestrado). Virginia Polytechnic Institute and State University, Blacksburg. Disponível em: <https://vtechworks.lib.vt.edu/bitstream/handle/10919/51361/Xiong_H_D_2015.pdf?sequence=1\&isAllowed=y> (Acesso em 16/08/2021) 
Yoder, E. J. e M. W. Wictzac (1975) Principles of Pavement Design. John Wiley and Sons, New York.

Zhao, H.; J. Yu e J. Ling (2010) Finite element analysis of Cymbal piezoelectric transducers for harvesting energy from asphalt pavement. Journal of the Ceramic Society of Japan. Tokyo, v. 118, n. 1382, p. 909-915. DOI: 10.2109/jcersj2.118.909

Zhao, H.; Y. Tao; Y. Niu e J. Ling (2014) Harvesting energy from asphalt pavement by piezoelectric generator. Journal of Wuhan University of Technology-mater. Sci. Ed., v. 29, n. 5, p. 933-937. DOI: 10.1007/s11595-014-1023-3 